\title{
Tiempo, legitimidad y trabajo. La metamorfosis del tiempo en la ética del trabajo
}

\section{José Durán Vázquez* \& Eduardo Duque**}

Resumen: Este texto se propone explicar el significado de las representaciones del tiempo vinculadas a la ética del trabajo postfordista. Para entender el sentido de estas representaciones se propone un análisis diacrónico. De este modo, el presente artículo se estructura en tres partes. Primeramente se describe la temporalidad de las sociedades preindustriales. En la segunda parte se muestra el proceso a través del cual el trabajo se elevó a la principal de las actividades humanas. Por último, en la tercera parte se analiza el significado de las concepciones del tiempo integradas en la ética del trabajo postfordista.

Para la realización de este trabajo se han utilizado fuentes secundarias de carácter histórico y sociológico. En la tercera parte se han utilizado también los textos producidos por los especialistas en managament y por los representantes de las principales instituciones políticas internacionales, que legitiman la actual ética del trabajo.

Palabras clave: Tiempo. Trabajo. Ética. Legitimidad. Orden social moderno.

\section{Time, legitimacy and work. \\ The metamorphosis of time at work ethics}

Abstract: This text aims to explain the meaning of the representations of time linked to the ethics of post-Fordist work. A diachronic analysis is proposed to understand the meaning of these representations. In this way, the present article is structured in three parts. First, the temporality of pre-industrial societies is described. The second part shows the process through which the work was elevated to the main of human activities. Finally, in the third part, the meaning of the conceptions of time integrated in the post-Fordist work ethic is analyzed.

For the realization of this paper secondary sources of historical and sociological character have been used. In the third part, the texts produced by the specialists in managament and by the representatives of the main international political institutions, which legitimize the current work ethic, have also been used.

Keywords: Time. Work. Ethics. Legitimacy. Modern social order.
Recebido: 11.10 .18

Aprovado: 30.04 .19
* José Durán Vázquez é doutor e licenciado em sociologia; licenciado em ciências políticas e em geografía e historia. Profesor de sociología na Universidad de Vigo, España.

Orcid: 0000-0002-

7440-0168.

<joseduran@uvigo. es>.

** Eduardo Duque
doutor em sociologia
pela Faculdade de
Ciências Políticas
e Sociologia da
Universidade
Complutense de
Madrid (2008),
mestre em filosofia
pela Universidade
do Minho (2002)
e licenciado
em teologia
pela Faculdade
de Teologia da
Universidade
Católica Portuguesa
(UCP-Braga) (1999),
Portugal.
Orcid: 0000-0003-
4719-3148.
<eduardoduque@
braga.ucp.pt>.




\section{Introducción}

a forma en la que viven y organizan su vida social los miembros de una determinada comunidad está directamente relacionada con su particular concepción del tiempo. Pero el tiempo no es sólo la realidad objetiva que configura y organiza la vida social. Es también el modo en el que cada sociedad desenvuelve y da sentido a su existencia habitando en una temporalidad que ella misma ha conformado. En otras palabras, no es que "cada sociedad tenga una manera propia de vivir el tiempo, sino que cada sociedad es también una manera de hacer el tiempo y de darle existencia" (Castoriadis, 1989: 73). Desde este punto de vista, se puede afirmar que el tiempo no es sólo un hecho externo que es asumido por los sujetos como parte de lo "dado por supuesto" (Berger \& Luckmann, 1997: 79 y ss), sino que se crea y se recrea a través de los múltiples procesos y relaciones que van tejiendo la vida social. Estas dos dimensiones de la temporalidad, una más objetiva y externa, la otra más subjetiva y apegada a los mundos de vida, se viven en nuestra época con una consciencia y una intensidad que no tienen precedente histórico.

No obstante, así como las sociedades no son homogéneas tampoco lo son los tiempos que las configuran (Duque, 2014: 157). Lo más común es que coexistan en una misma colectividad distintas concepciones y vivencias del tiempo, y que no todas ellas tengan la misma oportunidad de imponerse, sino sólo aquellas asociadas a los grupos sociales dominantes. Estas últimas pasarán a formar parte de la estructura de legitimaciones que dichos grupos utilizan para institucionalizar y legitimar su dominación. En este sentido, podemos afirmar que todas las formas de poder existentes a lo largo de la historia han creado e instaurado una determinada temporalidad.

\footnotetext{
El tiempo adquiere - ha escrito George Dumezil - un interés particular para cualquiera que, dios, héroe o jefe, quiera triunfar, reinar o fundar: éste, quienquiera, debe tratar de apropiarse del tiempo por la misma razón que del espacio (Iglesias de Ussel, 1987: 124).
}

Esta apropiación del tiempo varía en función del sistema de legitimaciones imperantes en cada sociedad. En las sociedades industriales los tiempos sociales dominantes son los que se vinculan con el mundo laboral, principal forma de legitimación y de estructuración de estas sociedades. Esta concepción del tiempo fue la que configuró y dio sentido a la ética moderna del trabajo.

Por ello, cuando las estructuras laborales y productivas se han transformado en las últimas décadas en los países industrializados, la representación del tiempo vinculada a los anteriores escenarios laborales ha tenido también que ser reformulada en relación con una nueva ética del trabajo más motivadora y movilizado- 
ra, que precisa también de otras formas disciplinarias. Las principales instituciones políticas internacionales, tales como la UE o la OCDE, así como los autores del managament, en cuanto principales legitimadores del nuevo orden laboral, han tenido un papel protagonista en la reconstrucción de esta nueva temporalidad. Una temporalidad que, por otra parte, tampoco es ajena a unos mundos de vida crecientemente individualizados. En este contexto el tiempo aparece con esa doble dimensión, objetiva y subjetiva a la que antes hemos aludido. Por una parte, tiene una vertiente abiertamente disciplinaria, al vincularse con los poderes políticos y empresariales que pretenden legitimarla. Por la otra se presenta como una oportunidad para que los sujetos construyan sus biografías laborales en entornos más abiertos y más libres.

Para entender el sentido de esta temporalidad proponemos un análisis diacrónico estructurado en tres partes. En la primera, se describe la concepción del tiempo predominante en las sociedades preindustriales. Un tiempo vivido fundamentalmente como una realidad objetiva e inmutable. A continuación, se muestra como las representaciones del tiempo que emergen con el inicio de la Época Moderna están en franca ruptura con la temporalidad anterior, y directamente relacionadas con el mundo del trabajo. Estas representaciones contribuyeron esencialmente a legitimar el orden social moderno. Un orden que demandaba sacrificios, pero que también otorgaba recompensas personales institucionalizadas. En la tercera parte, se analiza el proceso de transformación de esta temporalidad en relación con el cambio que experimentaron las estructuras laborales y productivas de las sociedades industriales a partir de mediados de los años setenta de la pasada centuria. En este contexto, ha surgido una nueva noción del tiempo amparada por las principales instituciones políticas nacionales e internacionales y por los ideólogos de la nueva gestión empresarial. Esta temporalidad es el resultado de la reformulación de la ética del trabajo anterior, en el ámbito de los nuevos escenarios laborales. Pero está también en relación con unas sociedades, como las actuales, cada vez más individualista y desinstitucionalizadas. Su propósito es movilizador y disciplinario. Pero las movilizaciones y las disciplinas a las que apela están en estrecha relación con los actuales contextos laborales y sociales.

\section{La temporalidad de las sociedades preindustriales}

En la introducción a este trabajo hemos señalado que cada sociedad tiene una determinada manera de concebir el tiempo en relación con su particular modo de organización social. Las sociedades preindustriales tenían una temporalidad completamente distinta a la nuestra. Entender esa temporalidad es entender también 
el cambio que supuso la institucionalización del tiempo moderno. Este será el propósito del presente epígrafe.

En las sociedades tradicionales el tiempo se percibía como un acontecimiento cíclico y repetitivo (Sue, 1995: 152 y ss), vinculado estrechamente con el orden también cíclico y repetitivo de la naturaleza (Hubert, 1992). En este contexto la dimensión temporal que realmente confería estabilidad y sentido al mundo era la del pasado (Elias, 1989: 64 y ss; Giddens, 1997: 75). Por ello, todo acontecer se percibía e interpretaba en relación con una tradición que era permanentemente recreada.

En este contexto, la novedad era rechazada cuando no podía ser interpretada de acuerdo con ese orden simbólico, con esa tradición, que se remitía permanentemente al pasado. Tradición que era periódicamente conmemorada y custodiada por los "guardianes del sentido" de estas comunidades (Balandier, 1989: 154). Es decir, por los que, perteneciendo a la élite del poder, la legitimaban y la sacralizaban convirtiéndola en dominante.

Esta imagen del tiempo fue compartida por las grandes civilizaciones del pasado. Griegos y Romanos, por ejemplo, percibían el cosmos como un orden cíclico y estable, inmutable y en equilibrio, al que se acomodaban también los asuntos humanos. La ruptura de este orden era interpretada como un indicio claro y cierto de degeneración. Por ello, todo cambio era rechazado, siempre y cuando supusiese la interrupción de esta armonía que gobernaba la vida natural y la humana.

La experiencia humana no podía ser otra que ésta, la de los acontecimientos que se sucedían integrados en este ritmo regular y estable. Por lo que toda novedad era interpretada como un periodo de interrupción y restauración del equilibrio perdido. Así lo enunciaba Marco Aurelio en sus Meditaciones:

El alma racional vaga alrededor del mundo y a través del vacío circundante mira hacia el tiempo infinito, y considera las periódicas destrucciones y renacimientos del Universo, y piensa que nuestra posteridad no verá nada nuevo y que nuestros antepasados no vieron nada más grande que lo que nosotros estamos viendo. Un hombre de cuarenta años que posea la más mediana inteligencia puede decir que ha visto todo lo pasado y lo futuro; así de uniforme es el mundo" (apud Bury, 2008: 25).

El Cristianismo rompió en principio con este orden cíclico del tiempo. En efecto, el tiempo era para el cristiano una secuencia única e irreversible, que se inauguraba con la creación Divina del mundo y el pecado original, y que culminaría algún día 
con el Juicio Final. El mismo Dios Jesucristo, hecho hombre, reforzaba esta idea del tiempo, señalando que la historia de la humanidad tenía lugar dentro del mundo, pero estaba encaminada a un destino final fuera de él, en un futuro no precisado. En este mismo sentido San Agustín comparaba la recta vía de los cristianos al círculo de los paganos (Sue, 1995: 152 y ss).

De acuerdo con este pensamiento, el cristiano medieval creía que estaba asistiendo a la etapa final de la historia, puesto que ya habían quedado atrás sus episodios más relevantes (Le Goff, 1969: 322-323). San Agustín, por ejemplo, afirmaba que el cristianismo representaba la vejez de la humanidad, y que el futuro nada podía deparar más allá de lo que había sido revelado.

Ahora bien, esta concepción del tiempo no era contraria, como tantas veces se ha admitido, a aquella otra de carácter cíclico que se remitía constantemente al pasado. El propio San Agustín señalaba en su De civitate Dei que la historia humana era cíclica y repetitiva. Únicamente se apartaba de este proceso el acontecimiento singular e irrepetible que comenzaba con Adán y Eva, y que finalizaba con el nacimiento y la muerte de Cristo (Arendt, 2003: 105 y ss).

El cristianismo contribuyó así a consolidar y a legitimar las representaciones del tiempo procedentes del mundo clásico greco-latino, y en este sentido sancionó también el pasado y la tradición, interpretándola de acuerdo con lo que se creía que era la voluntad Divina. Por ello, la Iglesia Cristiana condenó todas aquellas doctrinas que, procedentes de su mismo tronco, pretendían anunciar un futuro de promesas abiertamente contrarias al tiempo de la tradición sacralizado por la Iglesia (Bourdieu, 1999: 309).

Esta concepción del tiempo fue la predominante hasta la desaparición del Antiguo Régimen, cuando emergió una nueva sociedad basada en el trabajo y en la industria. Aunque esta transformación no será patente hasta finales del siglo XVIII y comienzos del XIX, mucho antes, desde finales de la Edad Media, comenzarán ya a observarse una serie de cambios, que si bien no impidieron que el tiempo dominante siguiese siendo el preindustrial, anunciaban una nueva era que va a eclosionar lentamente, hasta consolidarse con la Revolución Industrial.

\section{El trabajo como origen del progreso material y social del hombre}

En efecto, hacia finales de la Edad Media, en torno a los siglos XIII y XIV, en el Occidente Europeo se producirán una serie de pequeños cambios protagonizados por los nuevos mercaderes, cuyas actividades requerían un tiempo más planifi- 
cado, calculado y racionalizado. Este hecho no significaba en modo alguno que el tiempo cristiano ya no rigiese en las sociedades medievales. Tal circunstancia no tendrá lugar hasta después de la Revolución Industrial. No obstante, a partir de este periodo es posible ya observar en los centros urbanos donde la actividad comercial era más dinámica una serie de nuevos comportamientos que obedecían a otra manera de entender el tiempo.

Por ejemplo, los campanarios de las Iglesias ya no tendrán funciones exclusivamente de orden religioso, y estarán también destinados a anunciar el inicio de intercambios comerciales o de trabajos artesanales. Así ocurría, por ejemplo, en la ciudad de Artois, en donde el gobernador de Aire-Sur-la-Lys concedió el permiso para la construcción de un campanario desde donde se señalasen las horas de comienzo de los trabajos de los pañeros, así como de los intercambios comerciales. En otras zonas junto a las campanas se instalarán relojes, más apropiados para medir el tiempo de un modo más racional y abstracto, tal como requerían las actividades cuyo ritmo marcaban (Le Goff, 1983: 53 y ss).

No obstante, las concepciones del tiempo no sólo irán cambiando en razón de los nuevos actores económicos que tímidamente van instalándose en los centros urbanos del Occidente europeo. Los poderes políticos también tendrán interés en controlar el tiempo. Así es como hay que interpretar la proclamación que Carlos $\mathrm{V}$ hizo en 1370 para que la totalidad de las campanas de París estuviesen acompasadas con las del Palacio Real (Le Goff, 1983: 68 y ss).

Además de las actividades mercantiles y de los poderes políticos, tendrá también una importante influencia en el nuevo modo de relacionarse con el tiempo la Ciencia Moderna y el protestantismo, influencia que será ya perceptible desde los siglos XVI y XVII.

Galileo Galilei demostró por ejemplo, contra la opinión de la Iglesia que veía así amenazada su propia noción del tiempo, que la naturaleza no respondía a la voluntad Divina, sino que tenía sus propias leyes de funcionamiento, que podían ser desentrañadas racional y experimentalmente (Galileo Galilei, 1994: 18 y 41). Al tiempo teológico cristiano se oponía ahora el tiempo de la naturaleza. Ambos estaban guiados por principios o designios ajenos a la voluntad humana, y ambos querían reclamarse como tiempos destinados a gobernar las actividades humanas y las de la naturaleza. Por el momento era el tiempo teológico el dominante, pero más tarde acabaría por imponerse el tiempo de la ciencia (Elías, 1989: 118 y ss). 
La Reforma Protestante influyó también notablemente en la nueva representación del tiempo. El refugio que el creyente creyó encontrar en la profesión como claro designio de lo que Dios quería para él, significaba que el tiempo de vida pasaba a identificarse con el tiempo entregado a la profesión, como actividad austera, racional y planificada, como planificado, racional y austero era el tiempo de vida dedicado a ella (Weber, 1998, I). El tiempo adquiría así un carácter mucho más racional y cuantitativo, en franca oposición a aquel otro más espiritual y cualitativo que hasta aquel momento era el que predominaba.

Aun así, los acontecimientos que hemos citado no habrían tenido la misma influencia si la Revolución Industrial no hubiese consagrado las actividades laborales y las productivas como las más dignas y elevadas de todas cuantas podía emprender el ser humano. Estas ocupaciones pasaron así a ser identificadas con el progreso de la especie humana; progreso que no tendría límite, como tampoco lo tenían las actividades productivas y laborales, científica y racionalmente dirigidas.

No obstante, la idea de progreso no alcanzará toda su potencia ideológica asociada a las actividades laborales y productivas, mientras no se independizase de su asociación con los objetos y las cosas útiles y necesarias para satisfacer la vida material y social de los seres humanos. Mientras esto no se produjese, el volumen de la producción y el esfuerzo laboral necesario para llevarla a cabo se detendrían allí donde se entendía que estaban colmadas dichas necesidades. Dicho de otro modo, la noción de progreso encontraba su límite allí donde cada organización social fijaba sus propias necesidades sociales y materiales, de acuerdo con sus formas particulares de vida. El pensamiento Mercantilista y el de Adam Smith todavía permanecerán vinculados a una concepción como esta (Durán Vázquez, 2011: 83 y ss; 119 y ss). Este último consideraba, por ejemplo, que "el trabajo anual de una nación es el fondo que la surte originalmente de todas las cosas necesarias y útiles para la vida que se consumen anualmente en ella" (Smith, 1997: 5). En otras palabras, para el padre de la economía moderna, el trabajo no era aún una categoría exclusivamente económica, ya que atendía también a necesidades de tipo social.

No obstante, todas estas consideraciones con respecto al trabajo, que todavía amparaba la economía smithiana, irán cambiando a medida que se consolida la sociedad industrial con todas sus categorías económicas. Es posible seguir esta transición en la obra de David Ricardo. Desde su punto de vista, sólo serán valorados como objetos de consumo las mercancías que posean un determinado valor de cambio, esto es, aquellas en las que ha sido necesario depositar una cierta cantidad de trabajo para producirlas (Ricardo, 1959: 219-20). Desde este momento, 
el concepto de riqueza se desprenderá de todas sus acepciones de carácter social, que aún la lastraban, para integrarse dentro del sistema de acumulación capitalista, para el que la riqueza era el resultado de un proceso, cuyo motor principal era el trabajo, destinado a generar niveles cada vez mayores de riqueza. En este contexto emergerá una nueva noción de progreso íntimamente vinculada a un tiempo que se proyecta constantemente sobre un futuro de trabajo continuado, como continuado será también el crecimiento económico generado a partir de esta acción laboral siempre renovada. El tiempo pasará a ser así una dimensión impersonal y abstracta que extraerá todo su significado, no ya de su vinculación con la mejora de las condiciones materiales y sociales de la especie humana, sino de su relación con un sistema económico alimentado permanentemente con la fuerza del trabajo.

De acuerdo con este proceso, la historia será contemplada como el proceso a través del cual la humanidad se habría emancipado progresivamente de los poderes que la oprimían por la inmensa potencia liberadora del trabajo productivo. EI trabajo acabará siendo así considerado, tanto por el pensamiento socialista como por el marxista, como el origen de la propia humanidad, como la actividad a partir de la cual se perfeccionaban los individuos y progresaba la sociedad de una manera justa, libre y solidaria (Durán Vázquez, 2011: 130 y ss).

Todos los procesos, fuesen estos naturales o humanos, se creía que obedecían a la ley inexorable del progreso, que todo lo gobernaba. De todos modos, esta idea no se apoderó del común de las gentes hasta que la industrialización la hizo patente con sus enormes artefactos industriales y mecánicos (Bury, 1971: 290-291). Y hasta que la masa de los trabajadores no se convirtió en población asalariada, haciendo del trabajo la principal y única forma de vida.

No obstante, la salarización de los trabajadores conllevó importantes conflictos y luchas protagonizadas por los que no querían renunciar a sus modos tradicionales de vida, con los tiempos que a ellas iban asociados. En efecto, la economía moral de la multitud (Thompson, 1995), una serie de costumbres profundamente arraigadas, en virtud de las cuales el trabajo estaba poco racionalizado y entremezclado con las demás facetas de la vida, era completamente contraria al tiempo racionalizado y planificado que quería imponer la sociedad industrial (Thompson, 1979: 261). No era extraño, pues, que se produjesen conflictos protagonizados por los que no se resistían a perder sus tiempos de vida (Pollard, 235 y ss). Al final de este proceso, cuando la nueva mentalidad penetró en las mentes y en las costumbres de las gentes, "una sociedad de campesinos, artesanos y jornaleros polifacéticos se convirtió en una sociedad de trabajadores industriales 
modernos" (Pollard, 1987: 276). Una sociedad cuyos tiempos eran ya los propios de quienes consideraban que el trabajo era el principal medio de progreso individual y colectivo.

Aun así esta mentalidad no arraigó definitivamente hasta bien entrado el siglo XX (en Norteamérica en los años 20 y 30, y en Europa después de la Segunda Guerra Mundial). En efecto, cuando la mayoría de la población se integró en el mundo del empleo con unos salarios y unos derechos sin precedentes, la idea de progreso se extendió con una fuerza generalizada entre los miembros de la extensa clase media, que experimentaron un proceso de movilidad social nunca antes visto (Castel, 2001: 376).

Como clara muestra del espíritu generalizado de la época, el sociólogo británico T. H. Marshall escribía en los años 50, al comienzo de este periodo de casi tres décadas de crecimiento económico y prosperidad social:

La pregunta - comentaba con gran optimismo - no es si todos los hombres llegarán finalmente a ser iguales, que ciertamente no lo serán, sino si el progreso avanza constante, aunque lentamente, hasta que, al menos por su trabajo, todo hombre sea un caballero". Y se contestaba a sí mismo con el mismo tono: "Yo sostengo que sí avanza y que esto último ocurrirá" (Marshall, 1998: 18).

Esa creencia en el progresó cobró todavía más fuerza con la consolidación de la sociedad de consumo en los años 60 (Bocock, 1995: 29 y ss). La integración de los distintos estratos de la clase media en el mundo del consumo creó unas enormes expectativas sociales entre sus miembros. Como escribió un escritor español, retratando agudamente el sentir popular de la época, aunque no se aspirase a "ser más", no había que "ser menos" (Alonso, 2005: 34).

Esta pretensión de no quedar rezagado, de avanzar socialmente adquiriendo los numerosos y variados bienes que ofertaba la sociedad de consumo, estaba además en completa consonancia con los valores de independencia, libertad e igualdad que amparaba e impulsaba la cultura democrática (Lipovestky, 1990: 22 y ss).

Arraigó así profundamente en la conciencia de las élites, y también en la del conjunto de la colectividad, la idea de que la sociedad avanzaba lineal y gradualmente hacia un futuro que ofrecía cada vez más oportunidades de movilidad y de progreso social. Esta conciencia fue, además, un poderoso elemento de integración y de legitimación, porque otorgaba sentido al deseo de la población de prosperar personalmente, participando activamente en el mundo del empleo. 
Pero esta situación comenzó a cambiar a raíz de la crisis económica que se inició en las sociedades occidentales a mediados de los años setenta. A partir de este momento se abrió un escenario que difería profundamente del de la etapa anterior, caracterizado por un desarrollo económico y social sin precedentes. Todo ello influirá decisivamente en las estructuras temporales dominantes hasta ese momento. En efecto, ¿cómo podía mantenerse viva la idea de progreso, que se había articulado en buena medida alrededor del crecimiento económico y la estabilidad y el desarrollo en el mundo del empleo, cuando todas estas circunstancias se veían amenazadas por la profunda crisis que comenzó a mediados de los setenta? La necesidad de dar respuesta a esta nueva realidad llevó a las élites políticas y a las empresariales a manejar otra representación del tiempo de progreso más acorde con el nuevo contexto laboral y productivo, que resultase más integradora, movilizadora y legitimadora. Ahora bien, las imágenes del tiempo que así emergieron no eran el fruto de la capacidad creativa de estas élites. Fueron elaboradas con el lenguaje de los movimientos y de las ideologías que a lo largo de la modernidad habían hecho del trabajo la principal fuente de progreso, de integración y de justicia social (Durán Vázquez, 2011). Pero también a partir de los valores contraculturales que habían emergido en la sociedad de consumo a finales de los años sesenta. Valores de los que participaron más tarde también las clases medias. Se construyó así una representación del tiempo adaptada a las nuevas circunstancias laborales, pero también al espíritu de la época.

En el siguiente epígrafe analizaremos más en profundidad el contenido y el sentido de estos discursos que forman parte de una nueva ética del trabajo, que legitiman especialmente los defensores de la nueva gestión empresarial y las instituciones políticas internacionales, como la UE o la OCDE.

El futuro ya está aquí.

\section{Las representaciones del tiempo de la nueva ética del trabajo}

Las imágenes del tiempo asociadas a la nueva ética del trabajo estaban en relación, en efecto, con un nuevo modelo de organización de la producción y del trabajo, conocido como postfordista, que surgió a raíz de la crisis de mediados de los años setenta.

En esencia, esta crisis se caracterizó por una reducción muy acusada de los niveles de productividad de las economías occidentales, reducción que se tradujo en un aumento del paro y de la precariedad laboral. Estas circunstancias afectaron en 
mayor o menor medida a la mayoría de las economías de la OCDE entre mediados de los años setenta y comienzos de los ochenta (OCDE, 1997: 29), en las que el paro se triplicó (OCDE, 2000: 27). La crisis económica repercutió también muy negativamente sobre los del Estado del Bienestar, cuyos ingresos disminuyeron al tiempo que aumentaban también sus gastos (Rosanvallon, 1995: 67). En estas circunstancias el Estado del Bienestar aparecía como una rémora para la economía, pero una rémora imprescindible para mantener la estabilidad y la legitimidad de las sociedades occidentales (Offe, 1990: 139-142).

Como la crisis tenía, además, un carácter estructural, porque se debía a la incapacidad de las economías industriales para vender sus producciones en masa a una población saturada de bienes de consumo duraderos, la respuesta que dieron las organizaciones productivas a la misma fue también de carácter estructural (Piore \& Sabel, 1990: 263-264). En efecto, las economías occidentales reaccionaron optando por otro modelo productivo menos intensivo en mano de obra y más en tecnología, que producía en masa bienes de calidad, mucho más diversificados y singularizados, y que era además capaz de adaptarse a los cambios rápidos y constantes de la demanda (Piore \& Sabel, 1990: 273-274; Duque, 2012: 118). La consecuencia de todo ello fue que la productividad creció más que el empleo (Rifkin, 1996: 175 y ss; Beck, 2000: 46), con el consiguiente aumento el paro, y sobre todo de la precarización del trabajo (OCDE, 2000: 41; Beck, 2000; 2006: 67 y 97; Castel, 2001: 404). Las estructuras empresariales se hicieron, además, mucho más flexibles, con líneas de mando menos rígidas y trabajadores más polivalentes (Castells, 2000: 207; Gorz, 2000: 39 y ss).

La crisis supuso, en definitiva, que la relación tan positiva que se había establecido después de la Segunda Guerra Mundial entre crecimiento económico y empleo estable y duradero, relación que había alimentado fuertemente la idea de progreso, perdió, en el nuevo contexto productivo y laboral, buena parte del sentido que hasta este momento había tenido. Ni siquiera los que poseían cualificaciones académicas podían escapar a este escenario tan sombrío (OCDE, 2000: 53 y 114).

Por primera vez desde la Segunda Guerra Mundial las funciones de acumulación y las de salarización, que los Estados tenían que promover para potenciar el crecimiento económico y la integración social, eran contradictorias. El crecimiento de la productividad disminuía y, sobre todo, precarizaba el empleo. Para seguir impulsando ambos procesos, imprescindibles para el crecimiento económico, la estabilidad y la legitimidad de las democracias industriales occidentales, los Estados y las organizaciones empresariales se plantearon un cambio de estrategia (Duque \& Calheiros, 2013). Se trataba, como se afirmaba en un documento de la 
OCDE, de seguir "facilitando el acceso de todos al empleo", pero "aumentando la eficiencia y la flexibilidad del mercado de trabajo" (OCDE, 2000: 117-118).

Para adaptarse a las nuevas circunstancias los Estados del Bienestar no podían seguir funcionando como lo habían hecho desde los años cincuenta del siglo pasado, en una situación de crecimiento económico y de casi pleno empleo. Por una parte, eran cada vez más deficitarios; y por la otra, si se limitaban únicamente a la protección de los desempleados, podían alentar actitudes contrarias al empleo de aquellos que tenían menos posibilidades de encontrar un trabajo. Consciente de esta situación, la OCDE decía en su Informe del año 2000:

La protección social, en su forma exclusiva de transferencias de rentas, perpetuada durante un periodo prolongado, corre el riesgo de desalentar el retorno a la vida activa y, consiguientemente, de obstaculizar el ajuste del mercado de trabajo (OCDE, 2000: 120).

Por todo ello, se hacía imprescindible encontrar nuevas fórmulas para motivar a la población hacia el empleo. Una nueva ética del trabajo, que ya no podía descansar únicamente, como en la época anterior, en derechos sociales amparados y garantizados por los Estados del Bienestar (Serrano Pascual, 2009: 272). Como reconocía la Comisión Europea: "nuestras sociedades se ven impelidas a encontrar nuevos medios más apropiados para incitar a sus miembros a participar en la producción y en la vida social" (Comisión Europea, 1999: 53). Y estos medios iban a tener un carácter más individual, toda vez que se responsabilizaba al individuo de prepararse y de activarse para integrarse en el mercado laboral (Serrano Pascual, 2009: 273 y ss).

En el contexto de esta nueva ética del trabajo el tiempo va a adquirir un nuevo significado. Ya no podrá ser representado, tal como ocurriera en la etapa anterior, en relación con la idea de un futuro abierto a un progreso continuo y sin límite. En el nuevo contexto, en el que el crecimiento económico ya no se acompaña de la estabilidad en el empleo, y en el que los trabajadores tienen que estar permanentemente activos tratando de mejorar su empleabilidad, las principales instituciones políticas nacionales e internacionales, así como las élites intelectuales empresariales vinculadas al discurso del management, han construido una imagen del cambio como un proceso continuo y constante. "En nuestras sociedades - afirman los representantes del management reproduciendo este mismo discurso - el cambio se convierte en regla y la estabilidad en excepción" (Sérieyx, 1994: 72); "el cambio es la norma" (Drucker, 2000: 112).

El cambio se impone de este modo como un hecho casi natural y objetivo, que parece no obedecer a la acción de ningún agente o actor que lo impulse (Fairclough, 
2000: 13; Sennett, 2001: 102-103; Le Goff, 2002: 19). Los sujetos nada podrían hacer, pues, sino plegarse a sus exigencias, sometiéndose a un movimiento sin fin, siguiendo las reglas que establece este mismo movimiento (Le Goff, 2002: 21-22).

Ahora bien, como los "cambios no pueden predecirse" (Drucker, 2000: 140), afirman los gurús de la nueva gestión empresarial, como el cambio puede irrumpir en cualquier momento en la vida de los sujetos, no es posible programarlos tranquilamente. En otras palabras, no se puede ya encarar el futuro, tal como ocurría en la época anterior, con la confianza y la serenidad que otorga el saber que las cosas cambian, pero que lo hacen en una dirección positiva y cierta. Por el contrario, desde la óptica de los nuevos discursos laborales se insiste en que los cambios están instalados en la vida de los sujetos como una realidad imprevisible, por lo que éstos tienen que estar continuamente preparados, con una actitud activa y anticipativa. En palabras de los representantes de la OCDE, los individuos tienen que actuar "de manera preventiva, desarrollando capacidades para enfrentarse a ellos", a los cambios (OCDE, 1991: 155). Tratando, afirman los autores de la nueva gestión empresarial, de "llevar el propio futuro hacia el presente" (Landier, 1992: 206-207).

En esta misma línea de prever y de adelantarse al futuro hay que situar las llamadas Políticas Activas de Empleo, tales como las que la Unión Europea puso en marcha en la Cumbres de 1998 y el 2000, con el fin de movilizar a los trabajadores, de activarlos, descargando sobre ellos la responsabilidad de la formación continua para hacerlos así empleables (Serrano Pascual, 2000; 2009; Chassard \& Bosco, 1998).

Las élites políticas y empresariales han contribuido de este modo a legitimar una representación del tiempo que ya no se corresponde con la de la época anterior, en la que el presente se proyectaba tranquila y serenamente sobre un futuro de promesas aplazadas. En los nuevos escenarios laborales postfordistas esta ecuación ha cambiado casi por completo. Ahora es, en efecto, el futuro el que se pliega sin demora sobre el presente (Luhmann, 1992; 1996: 153 y ss), haciendo ver a los sujetos la necesidad de que se actualicen, de que se pongan al día permanentemente. La flecha del tiempo, que se proyectaba con firmeza hacia el futuro, y que se había convertido en la metáfora por excelencia de la primera modernidad, ya no representa, pues, fielmente la etapa actual (Duque, 2014). Podríamos decir, continuando con esta descripción metafórica de la realidad, que la imagen del boomerang se adecua mejor al momento actual. Porque, del mismo modo que el lanzador del boomerang está siempre dispuesto a enviar el objeto cada vez que a él regresa, los individuos tienen que estar también, en los nuevos entornos laborales, siempre preparados para anticipar situaciones, que cuando se anuncian como futuro, son ya presente (Durán Vázquez, 2009). 
Ahora bien, los nuevos discursos laborales no presentan únicamente esta vertiente negativa y disciplinaria, que obliga a los sujetos a estar siempre alerta. Se integran también en una nueva ética del trabajo que pretende movilizar y motivar a los trabajadores, en un momento de tanta precariedad e incertidumbre como el actual, en el que las trayectorias laborales son tan inciertas que se precisan nuevas justificaciones que legitimen y otorguen nuevos significados a la relación salarial (Boltanski \& Chiapello, 2002: 41 y ss). Las apelaciones de estos discursos no se quedan, pues, por ello en meras advertencias para que los trabajadores se plieguen continuamente a los requerimientos de un mercado laboral tan incierto. Su intención es, además, reencantar el mundo del trabajo, confiriéndole una serie de significados más acordes con los actuales ámbitos laborales. De ahí que se haya dicho que "jamás la función "irremplazable", "indispensable" del trabajo en tanto que fuente de "lazo social", de "cohesión social", de "integración", de "socialización", de "identidad personal", de sentido, ha sido invocada tan obsesivamente como desde que no puede llenar ninguna de esas funciones" (Gorz, 2000: 67, cursivas del autor).

De acuerdo con esta pretensión, los defensores de la nueva ética del trabajo presentan la inseguridad y los cambios permanentes y repentinos que caracterizan el actual mercado laboral, como una auténtica oportunidad para los sujetos.

Uno no puede permitirse hoy en día considerar su trabajo como un simple empleo - afirman los ideólogos de la nueva ética del trabajo: es necesario verlo de ahora en adelante como una pasarela que conduce a nuevas perspectivas de carrera (Genelot, 1992: 213).

Desde este punto de vista, el cambio se identifica con la creatividad y el desarrollo de las personas que trabajan en las organizaciones más innovadoras y abiertas:

Las empresas dispuestas al cambio - afirman los ideólogos de la nueva gestión empresarial - cultivan la imaginación para innovar...sus empleados son descubridores de ideas en busca de innovación, profesionales que persiguen conocimientos cada vez más completos... (Moss Kanter, 1999: 22)

En este contexto se ha producido un ataque frontal a las formas de organización del trabajo típicamente fordistas, a las que se acusa de haber creado un trabajador sumiso y robotizado.

La era del trabajador anónimo se ha acabado - dicen los autores del management postfordista. Esa era pesada del trabajador casi 
autómata de la cadena de producción en una factoría Ford...Esa era ha muerto. Bien muerta (Peters, 2002: 46).

Por el contrario, la nueva gestión empresarial se asocia con entornos laborales más dinámicos, igualitarios y participativos, en los que "por la calidad el trabajo podrá ser reencantado" (apud Le Goff, 1992: 152). El ámbito de trabajo se convertirá así - afirman los defensores de la gestión empresarial - "en un lugar vivo, un lugar donde la identidad individual puede desarrollarse sin exclusión ni alienación" (Genelot, 1992: 194) Se abandonaría así la "moral de sujeción" taylorista-fordista, para pasar a una "moral de cooperación libremente aceptada", la que sería característica de los nuevos entornos laborales (Landier, 1992: 177). Por esta vía las organizaciones empresariales dejarían de estar vinculadas con estructuras organizativas rígidas y autoritarias, para convertirse en verdaderos espacios de ciudadanía democrática. Espacios en los que "la divisa de la República - "libertad, igualdad y fraternidad" - está vigente en todas partes y para todos" (Sérieyx, 1994: 316).

Desde esta última perspectiva, la que intenta reencantar el trabajo creando una nueva ética laboral que motive y movilice a los sujetos en una época de precariedad e incertidumbre como la actual, el tiempo adquiere otras connotaciones. Ya no es únicamente una realidad objetiva y acuciante, que presiona constantemente a los sujetos para que éstos se sometan a sus dictados. Se identifica también, como decíamos anteriormente, con numerosas oportunidades. Desde este punto de vista se trataría, más que adaptarse al tiempo, de conquistarlo (Bauman, 2007: 129-130), de ir por delante de él para construir carreras laborales más ricas y dinámicas. Del trabajador se reclama así que sea un agente del cambio (Le Goff, 2002: 20), un sujeto que se implique y participe activamente en su ámbito laboral, para lo cual tendrá que estar siempre formándose y actualizándose. Pero esta actividad continua que no conduce a un destino de seguridad y estabilidad definitivas, es presentada también como un nuevo camino para progresar personal y socialmente (Boltanski \& Chiapello, 2002: 140-141). Las políticas de Activación que han puesto en marcha algunos Estados miembros de la Unión Europea, y que ha impulsado también la propia Institución Comunitaria, irían encaminadas precisamente no sólo a lograr la efectiva adaptación de los sujetos a las nuevas circunstancias laborales, sino también a conseguir que perciban esta adaptación como parte de un proceso de autonomización y desarrollo personal continuo (Serrano Pascual, 2009: 284). Se trataría así de "fabricar un hombre nuevo" (Le Goff, 2002: 20). Un hombre que no se reconozca en ninguna herencia. Que no confíe en ningún futuro que no sea el que él mismo pueda construir y anticipar una y otra vez a partir de sus propias habilidades y capacidades. La vida laboral se transforma 
así en un proceso de "deconstrucción creativa" sin fin, en una especie de obra de arte cuyo único "bricoleur" es el propio sujeto (Bauman, 2010: 179-180).

Ahora bien, a pesar de estas continuas apelaciones a la creatividad, a la iniciativa personal y a la autonomía de los sujetos, los nuevos discursos laborales tienen una intención claramente disciplinaria. No obstante, las normas y los principios que los constituyen en nada recuerdan ya a los de otra época. Pertenecen, en efecto, a otro orden disciplinario. No a aquel paternalista y autoritario, característico de las primeras fases de la sociedad industrial, que extraía de la tradición y del pasado todo su sentido. (Thompson, 1979; Pollard, 1987: 217 y ss). Ni tampoco a aquel otro de la época Fordista, extremadamente burocrático, jerárquico y rígido (Gaudemar, 1991; Bendix, 1966; Boltanski \& Chiapello, 2002), pero que sin embargo se proyectaba sobre un futuro de promesas aplazadas, haciendo más llevaderas las obligaciones y los esfuerzos que conllevaba (Bauman, 2006: 154 y ss; Sennett, 2000: 103). Un orden, por cierto, abiertamente criticado por los defensores de la nueva ética del trabajo, que anuncian con entusiasmo que "la era del trabajador anónimo se ha acabado" (Peters, 2002: 46).

Las disciplinas asociadas a la nueva ética del trabajo son efectivamente de otro tipo. Están más vinculadas a organizaciones horizontales y en red, que han de tomar decisiones de manera rápida en respuestas a cambios también rápidos de la demanda (Castells, 2000: 207). Organizaciones en la que sin embargo no están ausentes las estructuras disciplinarias (Boltanski \& Chiapello, 2002: 544; Sennett, 2000: 48). "Cierto afirman los intelectuales vinculados a la nueva gestión empresarial -, el control de la gestión no va a desaparecer" (Crozier, 1995: 29). Ahora bien, se trata de un control más difuso, que no se establece en base a líneas de mando y a jerarquías formalmente establecidas, con sus tiempos rutinarios y previsibles, sino a través de una cooperación más autónoma y participativa. A través de "disciplinas compartidas (que) facilitan el trabajo en equipo y permiten una flexibilidad organizativa" (Moss Kanter: 1999: 181). Pero que exigen también una vigilancia y una supervisión continua de los trabajadores, a veces incluso por parte de los propios compañeros de los equipos en los que se integran (Sennett, 2000: 121; Power, 1994). Estas formas de control se transforman en otras ocasiones en verdaderas autodisciplinas, en la medida en que son interiorizadas por los propios trabajadores, presionados como están por la constante necesidad de formarse continuamente.

Se crea así un escenario en el que "nunca se termina nada" (Deleuze, 1999: 6), en el que hay que estar siempre comenzando (Bauman, 2006: 37), demostrándose a uno mismo y a los demás que se es capaz, que se vale. Este es el único camino y también la meta. 
Ahora bien, si estas formas disciplinarias se han integrado plenamente en la nueva ética del trabajo, es porque están en relación con los valores sociales y culturales predominantes en las sociedades modernas. En efecto, muchas de las ideas contenidas en los textos de la nueva gestión empresarial relacionadas con la defensa de un trabajo más participativo, autónomo y creativo, proceden de la herencia común de la izquierda occidental, que también había criticado las formas capitalistas de producción como alienantes, autoritarias y antidemocráticas (Durán Vázquez, 2011: 312 y ss). En esta misma línea, pero en un contexto y con una finalidad completamente distinta, los autores del management postfordista consideran, citando expresamente a Marx, que las nuevas formas de gestión empresarial son "no alienantes", frente a las anteriores organizaciones en las que los empleados tenían "la obligación de callarse y obedecer" (Sérieyx, 1994: 312-313; Aktouf, 1999: 597). En franca oposición a estas estructuras organizativas, en las nuevas - consideran los que amparan la nueva gestión empresarial - los trabajadores "sienten de verdad que la divisa de la República - "libertad, igualdad y fraternidad" - está vigente en todas partes y para todos" (Landier, 1992: 177).

Ahora bien, además de haber integrado parte de las críticas que los movimientos de izquierda habían hecho a las estructuras laborales capitalistas, aunque adaptándolas a otras circunstancias y con otros propósitos, la nueva ética del trabajo ha asumido también los discursos de las distintas vanguardias y de los movimientos contraculturales (Boltanski \& Chiapello, 2002: 150, Le Goff, 2002: 119-120; Frank, 2011: 65). Dichos movimientos, herederos por otra parte de aquellas ideologías de izquierda, se habían distinguido por su rechazo más enérgico a la autoridad, al pasado y a la tradición, y también por sus deseos de autonomía, de independencia, de creatividad y de autenticidad (Le Goff, 2002: 97-122 y ss). Por sus ganas de vivir el presente con la mayor intensidad.

Estos valores se han ido consolidando en las sociedades occidentales a medida que sus miembros se iban independizando de sus ámbitos tradicionales de pertenencia, para integrarse gradualmente en los universos del trabajo y del consumo (Ewen, 1983; Beck, 2006: 215; Beck \& Beck-Gernsheim, 2003: 69 y 94). Lo cual significa, que si la nueva ética del trabajo se ha apropiado de estos valores, no ha sido incorporándolos desde otras esferas más o menos ajenas a esta ética, tal como se dice en alguna obra de amplia difusión (Boltanski \& Chiapello, 2002), sino porque formaban parte de la cultura común de las sociedades del trabajo y del consumo. Del modo en el que estas sociedades se articulan, se integran y se legitiman (Le Goff, 2002: 122 y ss).

Integrando todas estas ideologías y todos estos valores las estructuras disciplinarias a las que apela la nueva ética del trabajo aparecen como mucho menos opre- 
sivas y más liberadoras que las de otras épocas. Y el tiempo aparece en el contexto de esta ética con esa dimensión tan ambivalente, a la vez subjetiva y objetiva, tal como se ha mostrado a lo largo del presente trabajo.

\section{Conclusión}

La imagen del tiempo dominante en la nueva ética del trabajo presenta, en efecto, esa doble vertiente a la que hemos aludido anteriormente. Por un lado actúa como una realidad externa que los sujetos deben aceptar como un hecho inherente a la dinámica actual de las sociedades, porque es la "norma", por lo que vivir de otro modo sería quedarse rezagado, "fuera del tiempo". No queda pues más remedio que plegarse a sus dictados, a través de un proceso de adaptación continua y sin freno. Por otro lado, sin embargo, el tiempo aparece como una realidad más subjetiva, que los sujetos pueden aprovechar para construir una identidad laboral más autónoma y completa.

Lo singular de la situación actual es que, como decíamos al comienzo de este trabajo, estas dos dimensiones del tiempo, cuyo carácter es en muchas ocasiones claramente disciplinario, son vividas con un gran nivel de consciencia. Y aun así, no son, sin embargo, abiertamente contestadas. Quizás porque forman parte de la cultura común de las sociedades occidentales. Una cultura que se construyó en buena medida alrededor de la temporalidad de los universos del trabajo y del consumo. Primero, como tiempo de progreso en ruptura con el mundo tradicional anterior, y en relación con un futuro de crecimiento, de igualdad y de libertad casi sin límites. Después, en los años ochenta, cuando el mercado de trabajo se flexibilizó y se precarizó, y el del consumo experimentó un proceso de innovación, diversificación e individualización muy intenso, se fue institucionalizando una temporalidad vinculada al cambio permanente, pero también a una igualdad, a una autonomía y a una libertad más extremas. Esta temporalidad es aun plenamente moderna. La de una modernidad mucho más individualista, que ensalza los valores de la autonomía y de la libertad, y también los del progreso. Un progreso que no se concibe ya de otro modo sino es como actualización permanente

En este contexto se ha construido precisamente un nuevo orden disciplinario con su propia imagen del tiempo. No obstante, este tiempo ya no es el de la primera modernidad, que prometía un futuro de promesas aplazadas, pero que exigía a cambio la sumisión a instituciones rutinarias, jerárquicas y autoritarias, que sin embargo eran también fuente de estabilidad y de confianza. El tiempo que se impone en la actualidad en los distintos escenarios laborales ya no se vincula con esas jerarquías ni con esas rutinas, que son cada vez más refractarias a la cultura 
moderna. Pero tampoco con la confianza que proporcionaban. Pertenecen a otro orden institucional que concede todo el protagonismo al sujeto, pero que también descarga sobre él todas las responsabilidades y todos los riesgos (Beck, 2006: 215 y ss). En este orden así configurado el tiempo aparece con todas las ambivalencias de las sociedades actuales. Unas sociedades que se han liberado de las ataduras del pasado, e incluso de los sacrificios que exigía el tiempo de progreso que la primera modernidad había institucionalizado, para entregarse a un tiempo que no tiene más horizonte que el de un futuro que se está haciendo permanentemente presente. Este es el tiempo que legitima precisamente la nueva ética del trabajo.

\section{Referencias}

AKTOUF, Omar. Le management entre tradition et renouvellement. Montréal: Gaëtan Morin, 1999.

ALONSO BENITO, Luís Enrique; FERNÁNDEZ RODRIGUEZ, Carlos Jesús. Uso del trabajo y formas de gobernabilidad: la precariedad como herramienta disciplinaria. In: CRESPO, E.; PRIETO, C.; SERRANO, A. (Coords.). Trabajo, subjetividad y ciudadanía. Paradojas del empleo en una sociedad en transformación. Madrid: CIS, 2009.

ALONSO, Luís E. La era del consumo Madrid: S. XXI, 2005.

— Trabajo y ciudadanía. Madrid: Trotta, 1999.

ARENDT, Hannah. El concepto de historia: Antiguo y Moderno. In: ARENDT, H. Entre el pasado y el futuro. Ocho ejercicios sobre la reflexión política. Barcelona: Paidós, 2003.

BALANDIER, George. El desorden. Barcelona: Gedisa, 1989.

BAUMAN, Zygmunt. Mundo de consumo. Barcelona: Paidós, 2010.

- Vida de consumo. Madrid: FCE, 2007.

—. Modernidad líquida. Buenos Aires: FCE, 2006.

BECK, Ulrich. La sociedad del riesgo. Barcelona: Paidós, 2006.

_. Un nuevo mundo feliz. Barcelona: Paidós, 2000.

BECK, Ulrich; BECK GERNSHEIM, Elisabeth. La individualización. El individualismo institucionalizado y sus consecuencias sociales y políticas. Barcelona: Paidós, 2003. 
BENDIX, Reinhardt. Trabajo y autoridad en la industria. México: FCE, 1966.

BERGER, Peter L.; LUCKMANN, Thomas. Modernidad, pluralismo y crisis de sentido. La orientación del hombre moderno. Barcelona: Paidós, 1997.

BOCOCK, Robert. El consumo. Madrid: Talasa, 1995.

BOLTANSKI, Luc; CHIAPELLO, Ève. El nuevo espíritu del capitalismo. Madrid: Akal, 2002.

BOURDIEU, Pierre. Meditaciones pascalianas. Barcelona: Anagrama, 1999.

BURY, John. La idea de progreso. Madrid: Alianza Editorial, 1971.

CASTEL, Robert. Las metamorfosis de la cuestión social. Buenos Aires: Paidós, 2001.

CASTELLS, Manuel. La era de la información. v. I: "La sociedad red". Madrid: Alianza Editorial, 2000.

CASTORIADIS, Cornelius. La institución imaginaria de la sociedad. v. II. Barcelona: Tusquets, 1989.

CHASSARD, Y. ; BOSCO, A. L'émergence du concept d'employabilité. Droit Social, n. 11, p. 903-911, 1998.

COMISION EUROPEA. L'avenir du travail. Luxemburgo: Office des Publications Officielles des Communautés Européennes, 1999.

CRESPO, Eduardo; PRIETO, Carlos; SERRANO, Amparo (Coords.). Trabajo, subjetividad y ciudadanía. Paradojas del empleo en una sociedad en transformación. Madrid: CIS, 2009.

CROZIER, Michel. L'entreprise à l'écoute. Paris: Les Éditions du Seuil, 1995.

DELEUZE, Gilles. Conversaciones. Valencia: Pre-Textos, 1999.

DRUCKER, Peter. El management del siglo XXI. Barcelona: Edhasa, 2000.

DUQUE, Eduardo. É possível sair do presente? Uma teoria prospetiva. In: ARAÚJO, E.; DUQUE, E.; FRANCH, M.; DURÁN, J. (Eds.). Tempos sociais e o mundo contemporâneo - as crises, as fases e as ruturas. Braga (PT): Cecs, 2014.

— . Contributos para uma crítica da aceleração do tempo. In: ARAÚJO, E.; DUQUE, E. (Eds.). Os tempos sociais e o mundo contemporâneo. Um debate para as ciências sociais e humanas. Braga (PT): Cecs; Cics, 2012. 
DUQUE, Eduardo; CALHEIROS, Antônio. De que tempo se faz a relação entre a dromocracia e a democracia? Sitientibus, n. 48, p. 153-173, Feira de Santana, Jan. 2013, .

DURÁN VÁZQUEZ, José Francisco. La metamorfosis de la ética del trabajo. Constitución, crisis y reconfiguración de la ética del trabajo en la modernidad tardía. Santiago de Compostela (ES): Andavira, 2011.

. Del círculo a la flecha y de la flecha al boomerang: las representaciones del tiempo tardo-modernas en las esferas del trabajo y del consumo. Bararataria, Revista Castellano-Manchega de Ciencias Sociales, n. 10, p. 91-104, 2009.

DURÁN VÁZQUEZ, José Francisco; DUQUE, Eduardo. Culturas y generaciones. Actitudes y valores hacia la educación, el trabajo y el consumo en tres generaciones de jóvenes españoles. Aposta. Revista de Ciencias Sociales, n. 72, p. 129-165, 2017.

ELÍAS, Norbert. Sobre el tiempo. Madrid: FCE, 1989.

EWEN, Stuart. Consciences sous influence. Publicité et genèse de la société de consommation. Paris: Aubier Montagne, 1983.

FAIRCLOUGH, N. Representaciones del cambio en el discurso neoliberal. Cuadernos de Relaciones Laborales, v. 16, p. 13-35, 2000.

FRANK, Thomas. La conquista de lo cool. El negocio de la cultura y la contracultura y el nacimiento del consumismo moderno. Madrid: Alpha Decay, 2011.

GALILEO GALILEI. Cartas a Cristina de Lorena. Madrid: Alianza Universidad, 1994.

GAUDEMAR, J. P. El orden y la producción: nacimiento y formas de disciplina de fábrica. Madrid: Trotta, 1991.

GENELOT, Daniel. Manager dans la complexité. Paris: Insep Éditions, 1992.

GIDDENS, Anthony. Vivir en una sociedad postradicional. In: Beck, U.; Giddens, A.; Lash, S. Política, tradición y estética en el orden social moderno. Madrid: Alianza Editorial, p. 75-137, 1997.

GORZ, André. Miserias del presente, riqueza de lo posible. Buenos Aires: Paidós, 2000.

—. Metamorfosis del trabajo. Madrid: Sistema, 1997.

HEATH, Joseph; POTTER, Andrew. Rebelarse vende. Madrid: Taurus, 2005. 
HUBERT, Henri. Estudio sumario sobre la representación del tiempo en la religión y la magia. In: RAMOS TORRE, R. (Org.). Tiempo y sociedad. Madrid: CIS, 1992.

IGLESIAS DE USSEL, Julio. El tiempo en la sociedad contemporánea. In: VV.AA., Política y sociedad. Estudios en Homenaje a Francisco Murillo Ferrol. v. I. Madrid: CIS, 1987.

KOSELLECK, R. Futuro pasado. Barcelona: Paidós, 1993.

LANDIER, Henri. Hacia la empresa inteligente. Bilbao (ES): Deusto, 1992.

LE GOFF, Jacques. Tiempo, trabajo y cultura en el Occidente Medieval. Madrid: Taurus, 1983.

—_ La civilización del Occidente Medieval. Barcelona: Juventud, 1969.

LE GOFF, Jean Pierre. La démocratie post-totalitaire. Paris: La Découverte, 2002.

— La barbarie douce. Paris: La Découverte, 1999.

—. Le mythe de l'entreprise. Paris: La Découverte, 1992.

LIPOVESTKY, Gilles. El imperio de lo efímero. Barcelona: Anagrama, 1990.

LUHMANN, Niklas. Introducción a la teoría de sistemas. México: Anthropos, 1996.

- El futuro no puede empezar: estructuras temporales en la sociedad moderna. In: RAMOS TORRE, R. Tiempo y sociedad. Madrid: CIS, 1992.

MARSHALL, T. H. Ciudadanía y clase social. Madrid: Alianza Editorial, 1998.

MOSS KANTER, Rosabeth. Las nuevas fronteras del management. Barcelona: Paidós, 1999.

OCDE. Estudio sobre el empleo (Parte I). Barcelona: Universitat Autónoma OCDE, 2000.

_. Estudio sobre el empleo (Parte II) Madrid: Ministerio de Trabajo y Asuntos Sociales, 1997.

— Políticas de mercado de trabajo en los noventa. Madrid: Ministerio de Trabajo y SS, 1991.

OFFE, Claus. Contradicciones en el Estado del Bienestar. Madrid: Alianza Universidad, 1990. 
PETERS, Tom. La formación en la empresa del III milenio. Madrid: Nowtilus, 2002. PIORE, Michael J.; SABEL, Charles F. La segunda ruptura industrial. Madrid: Alianza Editorial, 1990.

POLANYI, Karl. La gran transformación. Madrid: La Piqueta, 1989.

POLLARD, Sidney. La génesis de la dirección de empresa moderna. Estudio sobre la revolución Industrial en Gran Bretaña. Madrid: Ministerio de trabajo y S.S., 1987.

POWER, Michael. The audit society. in Hopwood, A.; Miller, P. (Eds.). Accounting as social and institutional practice. Cambridge (UK): Cambridge University Press, 1994.

PRIETO, Carlos. Trabajo y orden social: de la nada a la sociedad de empleo (y su crisis). Política y Sociedad, v. 34, p. 19-32, 2000.

_ Crisis del empleo: ¿Crisis del orden social? In: Miguelez, F.; Prieto , C. (Coords.). Las relaciones de empleo en España. Madrid: S. XXI, 1999.

— (coord.). La crisis del empleo en Europa. Valencia: Germanía, 1999.

RICARDO, David. Principios de economía política y tributación. Madrid: Aguilar, 1959.

RIFKIN, Jeremy. El fin del trabajo. Barcelona: Paidós, 1996.

ROSANVAlLON, Pierre. La crisis del Estado Providencia. Madrid: Civitas, 1995.

SAAVEDRA, Luís. Ensayo sobre la riqueza. Madrid: Catarata, 2010.

SENNETT, Richard. La corrosión del carácter. Barcelona: Anagrama, 2000.

SÉRIEYX, Hervieux. El Big Bang de las organizaciones. Barcelona: Ediciones B., 1994.

SERRANO PASCUAL, Amparo. Regulación supranacional y despolitización del trabajo: el caso del paradigma de la activación.In: CRESPO, E.; PRIETO, C.; SERRANO, A. (Coords.). Trabajo, subjetividad y ciudadanía. Paradojas del empleo en una sociedad en transformación. Madrid: CIS, 2009.

- El concepto de empleabilidad en la estrategia europea de lucha contra el desempleo: una perspectiva crítica. Revista del Ministerio de Trabajo y Asuntos Sociales, v. 21, p. 137-149, 2000. 
SMITH, Adam. Investigación sobre la naturaleza y causas de la riqueza de las naciones. México: FCE, 1997.

SUE, Roger. Temps et ordre social. Paris: PUF, 1995.

THOMPSON, Edward Philip. Costumbres en común. Barcelona: Crítica, 1995.

— . Tiempo, disciplina de trabajo y capitalismo industrial. In: Thompson, E. P. Tradición, revuelta y conciencia de clase. Barcelona: Critica, 1979.

WEBER, Max. La ética protestante y el espíritu del capitalismo, In: Weber, M. Ensayos sobre sociología de la religión. v. I. Madrid: Taurus, 1998. 